\title{
Publisher Correction to: Electropolymerized-molecularly imprinted polymers (E-MIPS) as sensing elements for the detection of dengue infection
}

\author{
Clarisse E. Buensuceso ${ }^{1,2} \cdot$ Brylee David B. Tiu ${ }^{2,3,4} \cdot$ Luke P. Lee $^{4}$. Portia Mahal G. Sabido ${ }^{1}$. Guillermo M. Nuesca ${ }^{1}$. \\ Eugene B. Caldona ${ }^{5}$. Florian R. del Mundo ${ }^{1} \cdot$ Rigoberto C. Advincula $^{2,5,6}$
}

Received: 30 November 2021 / Accepted: 30 November 2021 / Published online: 8 December 2021

(c) Springer-Verlag GmbH Germany, part of Springer Nature 2021

\section{Publisher Correction to: Analytical and Bioanalytical Chemistry https://doi.org/10.1007/s00216-021-03757-y}

Unfortunately, in this article the labels to Fig. 6 were inadvertently converted. Therefore, the original version has been corrected. Please find the corrected version below:

The original article can be found online at https://doi.org/10.1007/ s00216-021-03757-y.

Rigoberto C. Advincula

rca41@ case.edu

1 Institute of Chemistry, College of Science, University of the Philippines Diliman, 1101 Quezon City, Philippines

2 Department of Macromolecular Science and Engineering, Case Western Reserve University, Cleveland, OH 44106, USA

3 Department of Biomedical Engineering, Case Western Reserve University, Cleveland, OH 44106, USA

4 Department of Bioengineering, University of California, Berkeley, CA 94720-1762, USA

5 Department of Chemical and Biomolecular Engineering and Joint Institute for Advanced Materials, University of Tennessee, Knoxville, TN 37996, USA

6 Center for Nanophase Materials and Sciences, Oak Ridge National Laboratory, Oak Ridge, TN 37830, USA 

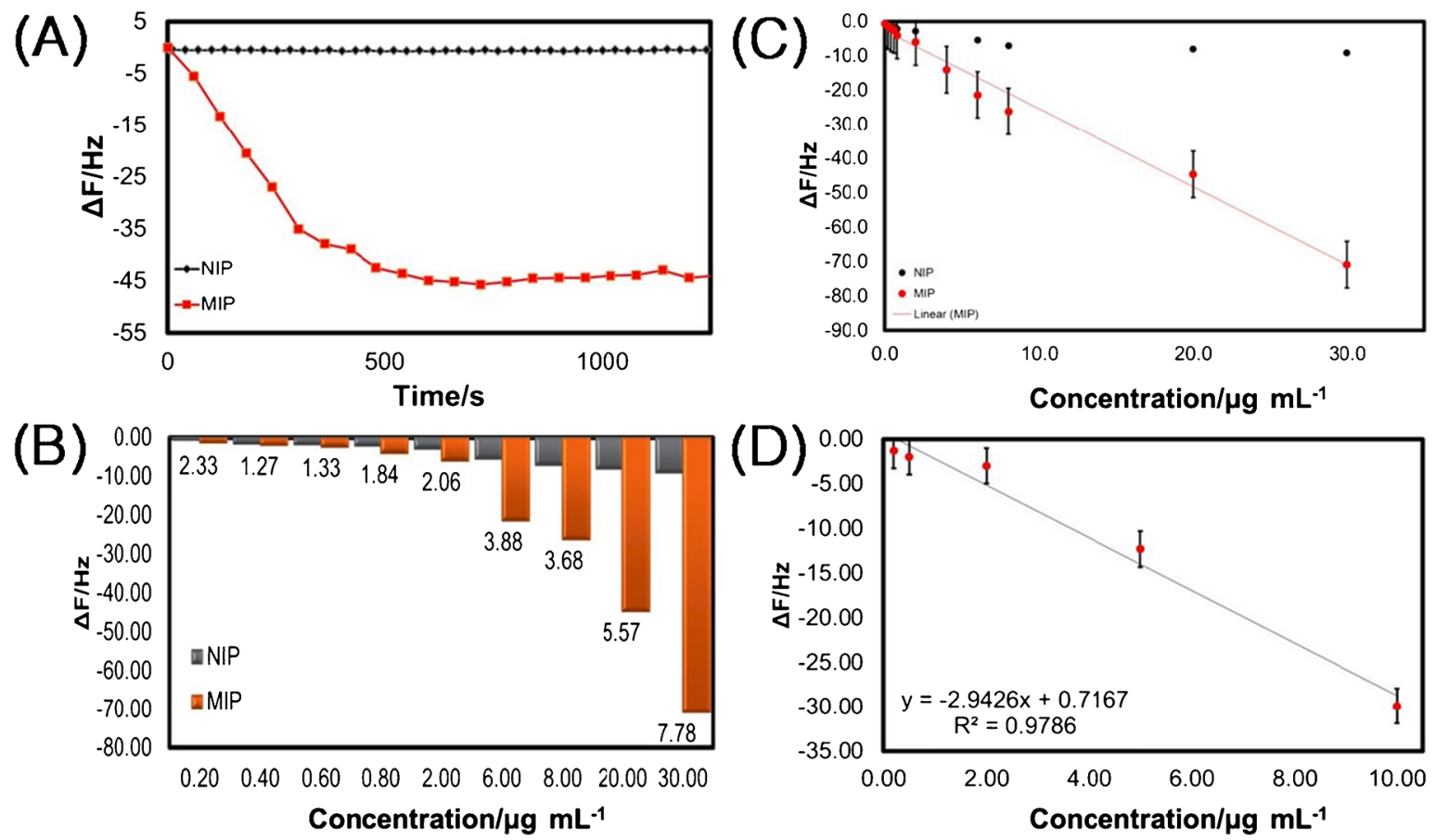

Publisher's note Springer Nature remains neutral with regard to jurisdictional claims in published maps and institutional affiliations. 